\title{
Genetic effects on human cognition: lessons from the study of mental retardation syndromes
}

\author{
P Nokelainen, J Flint
}

J Neurol Neurosurg Psychiatry 2002;72:287-296

The molecular basis of human cognition is still poorly understood, but recent advances in finding genetic mutations that result in cognitive impairment may provide insights into the neurobiology of cognitive function. Here we review the progress that has been made so far and assess what has been learnt from this work on the relation between genes and cognitive processes. We review evidence that the pathway from genetic lesion to cognitive impairment can be dissected, that some genetic effects on cognition are relatively direct and we argue that the study of mental retardation syndromes is giving us new clues about the biological bases of cognition.

See end of article for authors' affiliations

Correspondence to:

Dr J Flint, Wellcome Trust Centre for Human Genetics, Roosevelt Drive, Oxford OX3 7BN, UK; ¡@molbiol.ox.ac.uk

Received

9 February 2001

In final revised form

17 October 2001

Accepted

25 October 2001 n this review we ask what genetic research has told us about the molecular biology of human cognitive processes. We focus on the genes implicated in studies of cognitively impaired persons and we discuss what is known about their function. Our intention is to review a potentially fruitful approach for understanding the biology of cognitive processes-namely, the investigation of conditions where the genetic basis might be immediately related to the cognitive phenotype. The assumption here is that the genetic effect on behaviour will be close enough to the mutation for it to make sense to study gene products with no, or negligible, reference to environmental and other mediators of genetic expression.

We start with a note of caution. There are reasons to suspect that it will be difficult, if not impossible, to find examples where genetic effects act relatively immediately on cognition. Firstly, because genetic mutations operate throughout development, the phenotype could well be very far removed from the site of genetic action. For instance, a mutation could work by disrupting the expression of a series of developmental genes, which in turn determine tissue specific regulation in the adult of proteins directly controlling the phenotype of interest. Secondly, mutations are influenced by interactions with other genes. This can happen in several ways. The phenotype of a mutation will be affected by unlinked genetic variants (as is well known in other organisms ${ }^{12}$ ). Alternatively, the phenotype may arise as a consequence of changes far downstream of the mutation. There may be many different pathways affected, each with its own specific outcome. If these interact, attributing the final cause to the mutation, while true, does not tell us much about the immediate processes that give rise to the phenotype.

How might we find mutations with relatively direct effects on cognition? Most cases of cognitive impairment or of learning disability do not result from a mutation in a single gene. All the evidence on the genetic contribution to variation in intelligence quotients and attempts to find genes that influence such variation point to a polygenic genetic basis-that is to say, that variants of many, perhaps thousands, of genes contribute to the phenotype. Currently there is no convincing evidence that we have found any of these variants, although this is an active area of research. ${ }^{34}$ Therefore we can draw no useful information about the biological basis of intelligence from this work and it is not discussed here. For the same reason we have not discussed the genetics of reading disability (dyslexia) and autism. The interested reader is referred to recent reviews of these topics. ${ }^{56}$

One approach is to look at the genetic basis of non-syndromic mental retardation. By contrast with syndromic mental retardation, where the phenotype includes additional physical abnormalities (such as facial dysmorphism, minor abnormalities of the hands and feet), in nonsyndromic mental retardation the only abnormality is cognitive impairment. In conditions where there are no noticeable alterations in brain structure or when postmortem histopathological analysis seems normal, the cause of cognitive impairment is difficult to find and it is assumed that it may relate more directly to the genetic lesion.

As we shall see in the conditions that we review, there is some evidence that this is so. However, there is also evidence pointing in the other direction, as intriguing findings from two syndromic conditions, Fragile $\mathrm{X}$ and Prader-Willi syndromes, point to how cognitive defects arise from abnormal gene products. One of the surprises of the recent molecular discoveries is that syndromic and non-syndromic mental retardation can arise from mutations in the same gene.

Abbreviations: TM4SF, transmembrane 4 superfamily; MRX, X linked MR; IQ, intelligence quotients; IL IRAPL, IL I receptor accessory protein like; NCS, neuronal calcium sensor; GEF, guanine-nucleotide exchange factors; GAP, GTPase-activating proteins; GDls, guanine nucleotide dissociation inhibitors; NF1, neurofibromatosis type 1; MAPK, mitogen activated protein kinases; RSK2, ribosomal S6 kinase; HDAC 1, histone deacetylase 1; CREB, cyclic adenosine monophosphate response element binding protein; FRAXA, fragile $X$ syndrome; snoRNAs, small nucleolar RNAs; FOX, DNA binding domain termed forkhead; FMRP, fragile $X$ gene product 


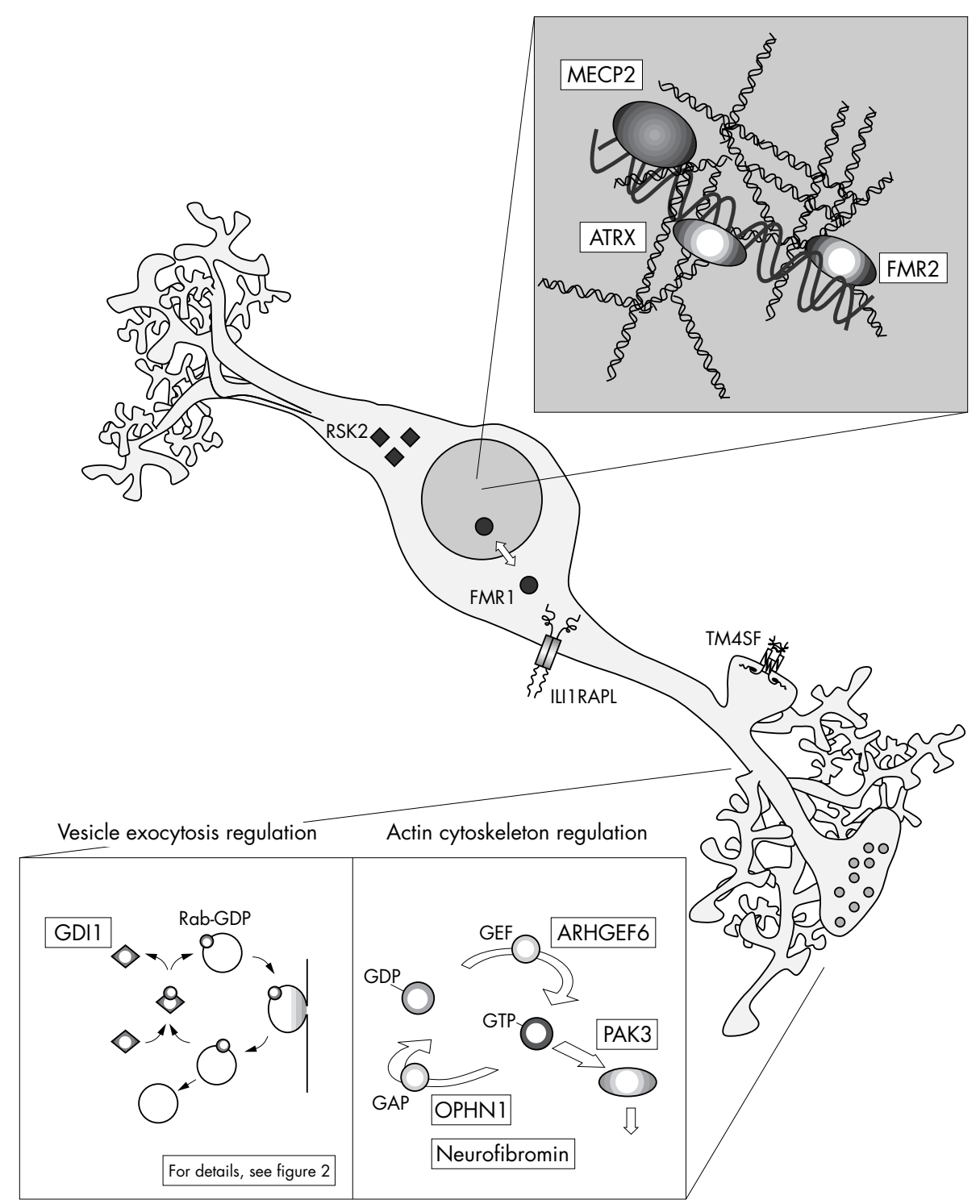

Figure 1 Schematic representation of a neuron. Four distinct classes of proteins have been implicated in mental retardation. Nuclear proteins MECP2, ATRX, and FMR2 may act as transcriptional regulators. FMR 1 has both nuclear and cytosolic localisation and may be able to shuttle between nucleus and cytoplasm. RSK2 is a cytosolic effector in the MAPK activated signalling pathway. The exact localisation of cell surface proteins TM4SF and ILIIRAPL is not well established, and the localisation and structure given here is purely illustrative. The regulators of Rho, Rab, and Ras-GTPases, OPHN1, ARHGEFF6, GDI1, and neurofibromin are all cytosolic. They are all, along with PAK3, implicated in vesicle excocytosis and actin cytoskeleton regulation.

Analysis of the range of mutations, a classic way of defining a gene's function, is revealing the pleiotropic nature of these genes. The results of this work show that the relation between phenotype and genotype in mental retardation is very complex. Together with an increasing knowledge of how the genes function (through the convergence of work on the genetic manipulation of model organisms and the molecular analysis of patients with mental retardation) the new work makes it possible to refer to the molecular and cellular basis of cognitive process, rather than to the medical conditions and the associated mutations. In this review therefore, we discuss the genes implicated in cognition and the processes in which they are involved.

For heuristic reasons, we have categorised the genes into four groups. Starting at the cell surface, we discuss first transmembrane and synaptic proteins, then we consider down stream signalling pathways (regulators of Rho and RabGTPase proteins, and MAPK activated pathways), next, proteins involved in intracellular traffic, and, finally, regulators of gene expression (fig 1).

\section{CELL SURFACE PROTEINS}

\section{TM4SF2 and the integrins}

Mutations in two related components of signalling at the cell surface have been implicated in cognition-namely, the tetraspanins and the integrins. ${ }^{7}$ Tetraspanins encode cell surface proteins that span the membrane four times. They form transmembrane complexes with integrins and consequently are likely to have an important role in the assembly of signalling complexes. Integrins are transmembrane receptors that provide a dynamic interaction between environmental cues and intracellular events. They function as $\alpha \beta$-heterodimers mediating adhesive interactions with the extracellular matrix and transduce signalling.

Two pieces of evidence point to the involvement of the integrins and tetraspanin transmembrane family of proteins in cognitive processes. Analysis of a drosophila mutant volado with a deficit in aversive classical conditioning, led to the discovery of an $\alpha$-integrin mutation ${ }^{8}$ The mutant was shown to have impairment in memory with normal sensorimotor 
abilities. ${ }^{9}$ Evidence for a role in human cognition came from the isolation of a mutation in a transmembrane 4 superfamily (TM4SF) gene in a patient with non-syndromic $\mathrm{X}$ linked mental retardation (MRX).

Molecular investigation of a female patient with $\mathrm{X} ; 2$ balanced translocation, who has mild mental retardation and minor autistic features, identified a chromosomal breakpoint that disrupted the third intron of the TM4SF2 gene..$^{10}$ Two different point mutations in the gene were found to be segregating with mental retardation in two MRX families. Patients have intelligence quotients ranging between $45-60$ in one family and 40-70 in the other. In the second family speech anomalies were the main feature. Analysis of the expression pattern of TM4SF2 showed that it is ubiquitously expressed from very early on in the differentiation of the mouse brain. In adult brains, a high level of expression was particularly evident in the hippocampus, parieto-occipital cortices, and olfactory cortex. TM4SF2 transcript was expressed in different layers of cortex and granular layer of the dentate gyrus as well as the pyramidal layer of the hippocampus, a distribution consistent with a role in learning and memory ${ }^{11}$

\section{IL1RAPL: a novel signalling pathway?}

Another cell surface protein ILIRAPL (ILl receptor accessory protein like) has been implicated in cognitive impairment through analysis of a patient with non-syndromic mental retardation. Much less is known about the protein's biology than is the case for integrin tetraspannin, but the available data indicate that it functions at the cell surface. The IL1RAPL gene was discovered by Chelly et al, who identified two overlapping microdeletions in Xp22.1-21.3 associated with non-specific mental retardation, the smaller covering 350 $\mathrm{kb} .{ }^{12}$ Using DNA sequencing from this region they discovered a gene showing weak homology with the Interleukin-1 receptor accessory protein. They went on to identify a point mutation segregating with mental retardation. The expression pattern of ILIRAPL mRNA on mouse brains is also consistent with a role in learning in memory as it is present in the granular layer of the dentate gyrus and pyramidal layer of the hippocampus. Down stream targets of ILIRAPL may include members of neuronal calcium sensors (NCS) ${ }^{13}$ In rat brain, NCS-1 has been localised to the Golgi apparatus and neurofilament structures, which might suggest a role in calcium regulated protein trafficking and cytoskeletal interactions. ${ }^{14}$

\section{SIGNALLING PATHWAYS \\ Regulators of Rho and Rab-GTPase proteins}

One of the most remarkable discoveries to have emerged from the molecular study of mental retardation syndromes is that mutations in the Ras signalling pathway occur in different $\mathrm{X}$ linked conditions. Of course, given that there are so many mental retardation syndromes whose genetic basis is not known, it is possible that, by chance, we have a biased view, that in fact once all the genes are found the causes will be very heterogeneous. Nevertheless it is a striking finding, suggesting mechanisms involved in the pathogenesis of intellectual disability.

The Ras proteins form a superfamily of small GTP binding proteins, which participate in signal pathways crucial for a wide variety of biological functions ${ }^{15}$ Central to their activity is the ratio of their GTP/GDP bound forms, the first being the activated one. This ratio is subject to complex regulation, illustrated in figure 2. The main known regulators of this ratio are guanine nucleotide exchange factors (GEFs), GTPase activating proteins (GAPs), and guanine nucleotide dissociation inhibitors (GDIs). The Ras superfamily of kinases includes Rho and Rab subfamilies, which are implicated in regulation of the actin cytoskeleton and vesicle excosytosis respectively. Members of the first family, small G proteins RhoA, Rac and

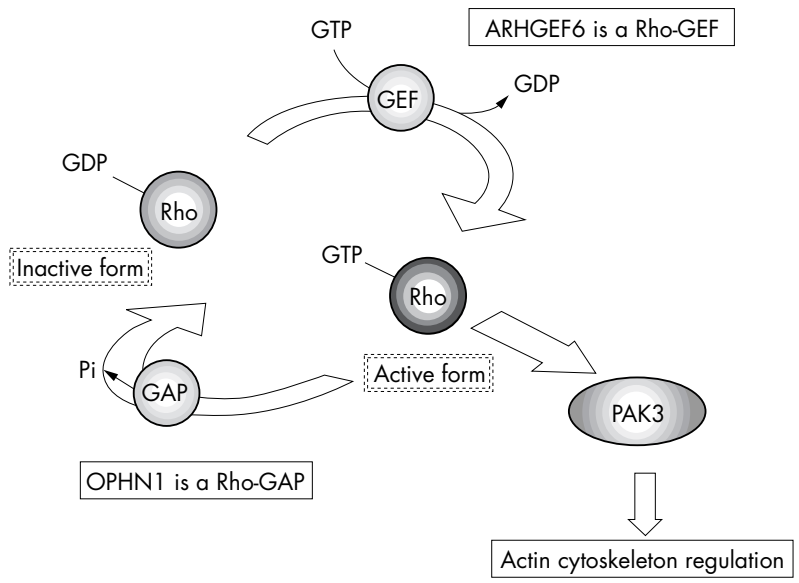

Figure 2 Rho-GTPase pathway: regulation of the actin cytoskeleton. Role of Rho-GTPases and their regulators. Ras proteins form a large family of kinases, which regulate many essential cellular signalling pathways. The Rho subfamily is implicated in regulation of the actin cytoskeleton and the Rab subfamily in vesicle excosytosis. These GTPases are active when bound to GTP and when that is hydrolysed to GDP, they are inactivated. Only in the activated GTP bound form can they interact with their downstream effector molecules. RhoA, Rac, and Cdc 42 are members of Rho subfamily and are key regulators of the actin cytoskeleton (collectively marked Rho in the diagram). They are also implicated as regulators of gene transcription in response to extracellular stimuli. In neurons they affect dendritic formation and axonal growth and in particular increase the number of axon terminals. The most abundant of the Rab subfamily is Rab3, which is expressed only in neurons and neuroendocrine cells. GDIl maintains the balance between the GTP-GDP bound forms. The vesicle excocytosis pathway is illustrated in the bottom of the diagram. GDP, guanine triphospahte; GTP, guanine triphosphate; GEF, guanine nucleotide exchange factor; GAP, GTPase-activating protein.

Cdc 42, are key actors in signal transduction regulating actin cytoskeleton $^{16}{ }^{17}$ and dendritic spine formation. ${ }^{18}$ The most abundant of the second is Rab3, which is expressed only in neurons and neuroendocrine cells.

Mutations in genes affecting different components of the Rho signalling pathway have been found in patients with non-syndromic mental retardation. Two proteins oligophrenin-1 (OPHN1) ${ }^{19}$ and ARHGEF $6^{20}$ directly affect the Rho activation cycle. OPHNI encodes a Rho-GAP protein that stimulates the intrinsic GTPase activity of the Rho, Rac, and Cdc42. The ARHGEF6 gene encodes a small cytoplasmic protein homologous to GEF for Rho-GTPases that activate them by exchanging Rho bound GDP for GTP. The third gene found mutated in MRX families is PAK3 (in MRX30). ${ }^{21}$ PAK3 may well be a downstream effector of the Rho-GTPases Rac and Cdc42 putting the message forward to the actin cytoskeleton $^{22}$ and to transcriptional activation. Finally, D'Adamo et al found mutations in GDI, a gene that encodes for another regulator of the GTP/GDP exchange cycle. ${ }^{23}$ GDIl inhibits GDP dissociation from Rab3a by binding to GDP bound Rab proteins and seems to be crucial in maintaining the balance between the GTP and GDP bound forms of Rab3.

How might the biology of the small GTP binding proteins explain human cognitive function? There is evidence that mutations in these genes are likely to disrupt normal development of axonal connections. ${ }^{15}$ Growth cones of developing axons find their way through the brain by sampling molecular signals, helped by GTPases. ${ }^{18}$ Whereas Cdc 42 and Racl are involved in the formation of lamellipodia and filopodia, ${ }^{24}$ inhibition of Rho, Rac, and Cdc 42 also reduces dendrite formation..$^{25}$ Perhaps cognitive dysfunction in these mental retardation families is due to a failure of neural networks involved in cortical development.

A second possibility (not exclusive of the first) is that synaptic function is compromised. This view is supported by the 
function of Rab3a. It is expressed only in neurons and neuroendocrine cells and localises to secretory vesicles. ${ }^{26}{ }^{27}$ Synaptic vesicles contain Rab3a, which is the most abundant Rab protein in the brain. In one model, excocytosis of synaptic vesicles leads to the dissociation of Rab3a from the vesicle. As Rab3a deficient mice have no fundamental deficits in synaptic vesicle excocytosis the protein is not essential to the process but is required to maintain a normal reserve of synaptic vesicles. The GDIl mutation, by disrupting RAB3a traffic, is expected to alter neurotransmitter release, which might, in turn, account for the intellectual impairment.

There is also evidence that the cognitive defects associated with neurofibromatosis type 1 (NFl) derive from an effect on the Ras pathway. NFl is a common familial tumour syndrome with an incidence of 1 in 3500. It is a Mendelian autosomal dominant trait affecting primarily brain and skin. Some $30 \%-$ $65 \%$ of the affected children have learning difficulties but only $4 \%-8 \%$ have mental retardation. ${ }^{28}{ }^{29}$ People with NFl seem to have impaired visual-spatial perceptual skills but language skills are also affected and these impairments tend to co-occur. Due to a lack of IQ matching in studies, it is not clear whether the language impairment is a specific consequence of NF1. Children with NFl are at increased risk of having learning problems but the cognitive profile of NFl includes both verbal and nonverbal impairments.

The protein encoded by the NFl gene, known as neurofibromin, contains a domain suggesting that it is involved in the Ras signal transduction pathways. ${ }^{30}$ Klose et $a l^{31}$ identified a loss of function point mutation that disables the Ras-GTPase activating function (RasGAP function). In the family they described, the affected children had an intellegence quotent range between 80 and 89 and impairment in both language and motor development. This tells us that RasGAP activity is needed for the development of cognitive functions. Possibly intact neurofibromin acts as a control element for Ras-GTP so that dosage dependent loss of the neurofibromin's RasGAP activity leads to higher concentrations of activated Ras-GTP. Neurofibromin is also associated with microtubules, which links it to cytoskeleton and signal transduction pathways, ${ }^{30}$ so that its effects may be mediated by axonal and dendritic development.

\section{RSK2: cytosolic effector in MAPK activated signalling pathway}

Investigation of a syndromic mental retardation condition, Coffin-Lowry syndrome, has led to the involvement of another signalling pathway in cognitive impairment-namely, the MAPK activated signalling pathway (MAPK stands for mitogen activated protein kinases). Coffin-Lowry syndrome is characterised by severe psychomotor retardation, facial and digital physical anomalies, and progressive skeletal deformation. The disorder was mapped by linkage to Xp22.22-34 and mutations found in a candidate gene RSK2 (ribosomal S6 kinase)..$^{35}$

Analysis of Coffin-Lowry syndrome provides a good example of the complexity of the relation between genotype and phenotype in cognitive impairment. Jacquot et al screened 37 patients whose phenotype was suggestive of Coffin-Lowry syndrome and found disease causing mutations in $25^{36}$ ( summarised in fig 3). All but two were unique and all caused loss of function. However, they found no consistent relation between severity of the phenotype and mutation type. Nor was there obvious correlation between a specific mutation and the expression of a particular clinical feature.

Manouvrier-Hanu et al reported a missense mutation in exon 7, changing an evolutionally conserved residue, which is present in all known RSK homologues. ${ }^{37}$ Their patients had atypical Coffin-Lowry syndrome. Early in childhood both brothers had severe hypotonia and relative macrocephaly, but after a few years the hypotonia resolved. Both children had facial features compatible with Coffin-Lowry syndrome and tapered fingers, but only mild mental retardation. Biochemical activity of the RSK2 protein was not studied.

Merienne et al tested the activity of the mutant RKS2 protein product in various MRX families. ${ }^{38}$ They found that the mutation in one family resulted in a fivefold to sixfold decrease in kinase activity. Because these patients showed no skeletal anomalies, some $15 \%-20 \%$ of the kinase activity is sufficient in normal MAPK signalling involved in skeletal development. Patients in this MRX family did not have any facial, digital, or skeletal anomalies compatible with CoffinLowry syndrome. Remarkably, they also presented with mild mental retardation, quite atypical for classic Coffin-Lowry syndrome. The mutation in this family was in nucleotide 1147 in exon 14 of the gene resulting in a conservative amino acid change.

These examples show how a distinction between syndromic and non-syndromic mental retardation may deceive us about the likely nature of genetic action. Both types of mental retardation can arise from mutations in the same gene. In this case, investigating non-syndromic mental retardation is no more likely than syndromic mental retardation to disclose a relatively unmediated genetic action on cognition.

What of the likely pathway from gene to cognition? Interestingly it may be linked to the Ras pathway already implicated in mental retardation. It is known that MAPK activates a CREB kinase, which in turn phosphorylates and activates CREB. CREB (cyclic adenosine monophosphate response element binding protein) is a transcription factor that regulates immediate early gene transcription. One CREB kinase turns out to be RSK2, forming part of a pathway whereby signals mediated by RAS and MAPK are transmitted to the nucleus to activate gene expression. ${ }^{39}$ However the extent of RSK2's involvement in neuronal development and exocytosis is unknown.

\section{INTRACELLULAR TRAFFIC \\ FMR 1}

Fragile $\mathrm{X}$ syndrome (FRAXA) is the commonest cause of inherited mental retardation, affecting 1 in 4000 males. ${ }^{40}$ It is due to an expansion of a trinucleotide repeat in the 5' untranslated region of gene coding for an RNA binding protein that exists in six isoforms. Two types of expansion are recognised, the full mutation consists of greater than 230 trinucletoide repeats. Premutations consist of between 60 to 200 repeats; the full mutation is abnormally methylated on the $\mathrm{X}$ chromosome of males and the active $\mathrm{X}$ chromosome of females.

The full mutation causes mental retardation in all males and in about $60 \%$ of females, but there is extensive phenotypic variation in both sexes. In most cases there is a poor relation between the degree of cognitive impairment and the presence of a full or premutation, almost certainly due to the presence of mosaicism, whereas concentrations of protein provide a much better index. ${ }^{41}$ Mildly impaired fragile $X$ males have been described, in whom unmethylated expansions are found in a large proportion of cells. ${ }^{42}$ Furthermore, levels of mosaicism vary between tissues, ${ }^{43}$ so that it is not possible easily to draw conclusions from findings in leucocytes; this probably explains the weak correlation between proportion of active $X$ chromosomes carrying the mutation in females and the degree of cognitive impairment. ${ }^{44}$

Although the genetic basis of fragile $X$ syndrome was uncovered 10 years ag $^{45-48}$ the function of the gene has remained mysterious. The gene is referred to as FMRl, for fragile X mental retardation. There is more than one fragile site on the $\mathrm{X}$ chromosome (see later for a discussion of a gene found to lie next to the FRAXE fragile site) so the FMR gene at FRAXA is called FMRl. The associated protein is termed FMRP. FMR protein is known to export mRNA from the 
A

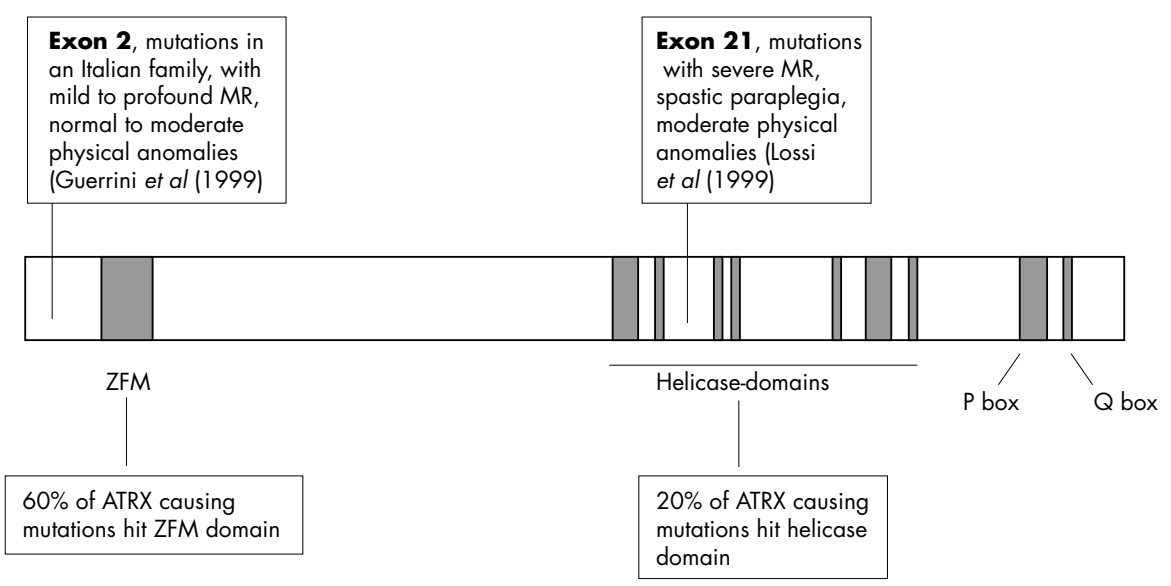

B

Female DZ68, mild MR
and developmental delay

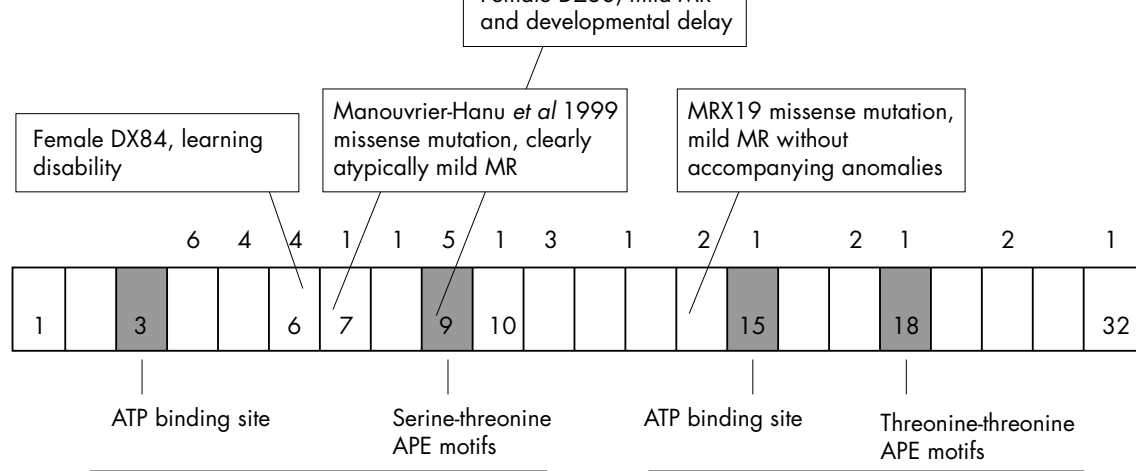

Catalytic domains for

Catalytic domains for $\mathrm{N}$-terminal protein kinase,

C-terminal protein kinase

responsible for substrate phosphorylation

C

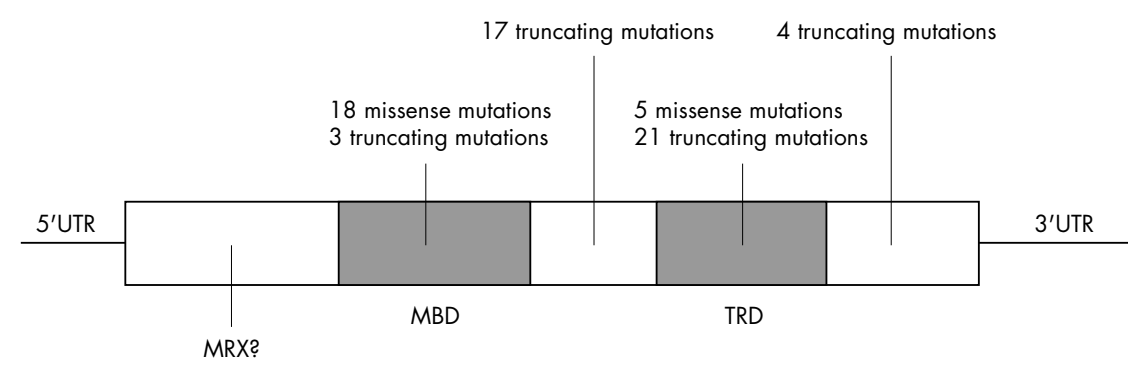

Figure 3 Structure of MeCP2, ATRX, and RKS2 showing the placement of functional domains and mutations that have been associated with mental retardation. (A) The structure of the ATRX gene. ZFM, zinc finger motif (also known as PDH for plant homeodomain) thought to interact with histone deacetylase 1 (HDAC1). Up to $60 \%$ of ATRX causing mutations are located in the ZFM domain. The helicase domains identify ATRX as a novel member of the SNF2 family and some $20 \%$ of the ATRX causing mutations are located in this region of the gene. The P-box element is present in all members of the SNF2 family. Q-box is a glutamine rich stretch in the predicted product, which serves as potential protein-protein Binteraction domain. (B) Structure of the RKS2 gene. Exons 1-22 are drawn as boxes (not to scale). Numbers above exons refer to the number of mutations described by Jacquot et al. ${ }^{37}$ (C) Structure of the MECP2 gene. Only three exons form this gene; exon boundaries have been omitted. MBD, methyl binding domain; TRD, transcriptional repression domain.

nucleus but how this might relate to the cognitive phenotype has been unclear. In normal brain, the FMR protein is found in nearly all neurons. It can bind RNA, including its own transcript, and it has been postulated that the FMR protein has a role in the machinery of translation and, as it shuttles between nucleus and cytoplasm, it may be involved in mRNA export. ${ }^{49}{ }^{50}$ Functional studies have yielded few clues. FMRI knockout mice have macro-orchidism and impaired spatial learning abilities. ${ }^{51}$ Biochemical and immunofluorescence studies show a tight colocalisation of FMR protein with cytoplasmic ribosomes, as seen for translation factors. ${ }^{52-54}$

Our understanding of the pathogenesis of mental retardation in fragile $\mathrm{X}$ syndrome has been considerably advanced by work on dendrites. Most of the grey matter in the human cortex consists of dendrites, the processes that emerge from the bodies of neurons and provide the site for synapses, yet their size and complexity has impeded experimental investigation. Recently, however, it has been possible to demonstrate that 
dendrites perform computational tasks, ${ }^{55}$ transforming presynaptic inputs into a signal delivered to the cell's axon. The relative computational autonomy of dendrites goes along with another discovery, that they control local protein production, critical for the development of long lasting synaptic change and a putative molecular substrate of learning and memory. ${ }^{56-59}$ New protein synthesis requires mRNA and it is now clear that qnewly synthesised mRNAs are targeted to dendrites. ${ }^{60}{ }^{61}$ The importance of this observation is that FMRP is synthesised in dendrites.

Greenough et al, investigating the mechanisms whereby synapses are formed in response to experience, made the discovery that FMRP is involved in the synaptic regulation of protein synthesis. ${ }^{62}$ They found that stimulation of a preparation of presynaptic terminals resulted in a rapid rise in the association of ribsosomes with mRNAs and a concomitant increase in protein synthesis. Arguing that only a subset of mRNAs would be involved in this response, the researchers sought for message that was enriched in the presynaptic terminals. They found a striking increase in polyribosomal association of one mRNA, which turned out to be the transcriptional product of the fragile $X$ gene. ${ }^{63}$ Subsequently they have shown that FMRP concentrations are increased in animals learning new motor skills ${ }^{64}$ and that humans with fragile $X$ syndrome show immature dendritic spine morphology. ${ }^{65}{ }^{66}$ There is also evidence that neurotransmitter evoked protein synthesis is reduced in vivo, ${ }^{62}$ strengthening the suggestion that one role of FMRP in normal brains is to regulate the localised translational response to synaptic stimulation, a prerequisite for the synaptic plasticity that is thought to underlie many forms of learning and memory. This in turn could explain why mental retardation is a consequence of a mutation in the FMRl gene.

\section{Small nucleolar RNAs in Prader-Willi syndrome}

Prader-Willi syndrome, a rare cause of syndromic mental retardation, has attracted a lot of attention because of the unusual genetic mechanism that gives rise to it. Prader-Willi syndrome and Angelman syndrome arise from deletions of a small region of $15 \mathrm{q} 11-\mathrm{q} 13 .{ }^{67}$ The two syndromes have characteristic and distinct neurobehavioural profiles: in Angelman syndrome, the retardation is severe (very few affected persons can talk) and there is ataxia, seizures, hyperactivity, and paroxysmal laughter. By contrast, in Prader-Willi syndrome the mental retardation may be only mild and there is a specific behavioural abnormality: hyperphagia resulting in severe obesity.

\section{"There has been remarkable progress in delineating the genetic basis of mental retardation and we now have clues as to which pathways are involved in cognition"}

The basic genetic defect is not simply a dosage effect, due to a loss of chromosomal material on 15q11-q13; it turns out that about a quarter of cases of Prader-Willi syndrome are not due to a deletion but to the inheritance of two maternal copies of chromosome 15 (rather than the usual situation of one maternal and one paternal). Conversely, two paternal copies of chromosome 15 result in Angelman syndrome. The chromosomal region is said to bear a parent of origin imprint, of which the molecular signature is a difference in DNA methylation. Seven genes (and candidate genes) have been identified in the Prader-Willi syndrome region, all of which seem to be brain specific. ${ }^{68}$ It is not known if the phenotype is due to an abnormality in a single gene. However there is now some evidence to suggest that the defect in Prader-Willi syndrome is mediated by abnormal RNA editing, due to misregulation of guide RNAs.

The nucleolus contains many small RNAs, termed small nucleolar RNAs (snoRNAs); most of these snoRNAs function in the post-transcriptional modification of rRNA nucleotides. However, it is now clear that the action of methylation guide snoRNAs goes beyond the field of ribosome biogenesis. Recently three brain specific snoRNAs, which are subject to genomic imprinting in mice and humans, have been discovered within the $15 \mathrm{ql} l$ critical region for Prader-Willi syndrome and Angelman syndrome. ${ }^{69}$ Unusually they do not have appropriate antisense elements, so their function is not clear, but one has an 18 base pair similarity to the mRNA encoded by the gene for the serotonin receptor $2 \mathrm{C} .{ }^{69}$ The sequence matches a conserved region subject to both alternative splicing and adenosine to inosine editing. Because of the known involvement of serotonin in appetite control and cognition, ${ }^{70}$ this finding raises the intriguing possibility that the defect in Prader-Willi syndrome involves a defect in serotonin neurotransmission.

\section{TRANSCRIPTIONAL REGULATION}

The involvement in mental retardation of genes that affect the expression of other genes, in other words transcriptional regulators, is to be expected. So many mental retardation syndromes have a complex phenotype, involving multisystem abnormalities, that a mutation in a gene with broad effects is a likely cause of mental retardation. In many cases transcriptional regulators influence diverse biochemical pathways, including developmental, so they are good candidates. Four mental retardation syndromes are now known to be due to mutations in transcriptional regulators. Two of these genes function by altering the structure of chromatin.

Gene transcription is in part controlled by the extent to which the DNA is made accessible to the transcriptional machinery. DNA does not exist in a free state in the cell; it is closely associated with a complex of proteins called chromatin, which we now know is intricately involved in DNA metabolism. ${ }^{71}$ DNA has to be free of nucleosomes for it to be accessible to transcription factors and the large complex of proteins that constitutes RNA polymerase. Understanding what controls chromatin packaging will therefore reveal one way of controlling gene expression. For this reason there has been much interest in characterising proteins that remodel chromatin and consequently influence many biochemical pathways, including the control of genes involved in the development and activity of the CNS.

\section{MECP2 and Rett syndrome}

Rett syndrome is an X linked pervasive neurodevelopmental disorder that affects between 1 in 10000 to 15000 girls. ${ }^{72}$ The phenotype of the affected girls is distinctive with developmental arrest at the age of 6-18 months. From then on the girls progressively lose purposeful hand use as well as all communication skills. Autistic features emerge and classically they show hand wringing and other repetitive hand movements. After a rapid deterioration, a stable period is reached and most girls survive into adulthood. Rare male cases have been described. $^{73}$

The molecular study of Rett syndrome provides another good example of the difficulty of relating phenotype to genotype. As with Coffin-Lowry syndrome, and with the ATRX syndrome discussed below, it furnishes an example of how syndromic and non-syndromic mental retardation can arise from mutations in the same gene (summarised in fig 3). ${ }^{74-76}$

Rett syndrome is due to mutations in MECP $2,{ }^{77}$ a protein that binds to one of the constituents of chromatin. ${ }^{78}$ Our understanding of the biochemistry of MECP2 does nothing to explain why mutations should give rise to a mental retardation syndrome. The protein binds methylated CpGnucleotides throughout the chromosome, ${ }^{79}$ promoting chromatin compaction and thereby turns off gene transcription. ${ }^{80-82}$ MECP2 has a multitude of downstream targets, which currently remain unknown. So why is the brain so 
vulnerable to MECP2 mutations? The presence of alternative transcripts might provide a solution, as they show a differential expression pattern. ${ }^{83}$ The gene is highly expressed in foetal brain where the largest $10 . \mathrm{kb}$ transcript is the predominant isoform.

\section{ATRX}

Pleiotropic effects are also seen in the ATRX syndrome. ${ }^{84}$ Patients with ATRX have severe mental retardation, $\alpha$-thalassaemia, characteristic facial appearance, profound developmental delay, neonatal hypotonia, and genital abnormalities. ATRX syndrome is due to mutations in a transcriptional regulator that is located on the long arm of the $\mathrm{X}$ chromosome. ${ }^{85} 86$

Gibbons and Higgs ${ }^{84}$ reviewed the phenotype and genotype of 145 cases from over 80 families. Figure 3 shows the position of these mutations and functional domains of the predicted protein product. Again we see a complex picture, with both syndromic and non-syndromic mental retardation being reported. Remarkably, a family has been described where mutations result in only mild mental retardation and adequate language skills. Two family members were able to hold unskilled jobs, leading relatively independent lives. ${ }^{87}$ One other affected family member had moderate mental retardation and limited independence, whereas the fourth showed profound mental retardation. Martinez et al also described patients who expand the phenotypic range of ATRX mutations. ${ }^{88}$ Their patients had neonatal hypertonia (opposite to hypotonia normally seen in ATRX) and later developed spastic paraplegia. They also had milder physical anomalies.

As with Rett syndrome, understanding the biochemistry of the ATRX protein casts no light on the origins of the cognitive impairment. The mutated gene belongs to the SNF2 family of proteins and contains a PHD finger (a putative zinc binding domain), and a motif that relates ATRX to a group of proteins called helicases. ${ }^{89}$ Other members of this group of proteins are known to bind to chromatin and ATRX may be involved in chromatin remodelling, considered to be a crucial step in the control of gene expression. Recent findings suggest that ATRX may be part of the complexes that histone deacetylase forms with proteins that have a methyl binding domain, such as MECP2. ${ }^{86}$ We will need to know far more about the downstream effects of both mutations to relate behavioural phenotype to genetic lesion.

\section{FMR2}

A second fragile site on the $\mathrm{X}$ chromosome, termed FRAXE ( to distinguish it from other fragile sites, including FRAXA discussed above), is associated with a rare non-syndromic mental retardation condition, with estimated prevalence less than 1 in $23000 . .^{90-92}$ In general, patients with FRAXE exhibit various learning difficulties, such as speech delay and reading and writing problems. ${ }^{93}$ As with FRAXA, a trinucleotide expansion occurs at the fragile site, leading to the inactivation of a nearby gene, known as FMR2. The FMR2 gene is almost certainly another example of a transcriptional regulator.

\footnotetext{
"Many cases of idiopathic mental retardation, whether mild, moderate, or severe, could be due to mutations in the genes that have already been identified"
}

The FMR2 protein shows similarity to nuclear transcription factors and has been shown to contain two functional nuclear localisation signals. ${ }^{94}$ Miller et al found that in mice the FMR2 is localised in neurons of the neocortex, cerebellar Purkinje cells, and the granular cell layer of the hippocampus ${ }^{95}$ They suggested that FMR2 may play a part in modulation of gene expression in learning and normal behaviour.

The genotype-phenotype correlation in males with FMR2 mutations is not straightforward. Some males have no pheno- typic abnormalities, yet have a trinucleotide expansion, a fully methylated CpG island, and no expression of FMR2. Gedeon et al described two unrelated boys (CB and MK), with overlapping submicroscopic deletions distal to FRAXE. ${ }^{96}$ MK had a smaller, less than $100 \mathrm{~kb}$, deletion completely overlapped by the $200 \mathrm{~kb}$ deletion of CB. MK had only speech delay, while $\mathrm{CB}$ had global developmental delay, including speech delay. Both of them had mild physical anomalies, but had epicanthal folds in common. Gecz et al went on to show that some exons of the FMR2 were deleted in $\mathrm{CB}^{97-98}$ They also described two unrelated families, where male probands showed mild mental impairment and/or learning difficulties cosegregating with lack of FMR2 expression. ${ }^{99}$ The problem is further complicated by recent reports of an FMR3 gene, which is also transcriptionally silenced in FRAXE full mutations. ${ }^{100}$

\section{FOXP2}

Recently the molecular basis of another rare non-syndromic mental retardation syndrome has been found to be a transcription factor, called FOXP2. The syndrome exists in a single three generation pedigree in which a severe speech and language disorder is transmitted as an autosomal dominant monogenic trait. ${ }^{101-104}$ The phenotype is particularly intriguing because it involves deficits in speech and language. For instance, family members produce plurals of familiar but not unfamiliar words and fail to generate inflected forms of regular but not irregular verbs. The language impairment is part of a broader syndrome, which includes impairment in articulation, a praxic deficit that also involves non-linguistic oral and facial movements. ${ }^{105}$

After genetic mapping of the disorder to chromosome $7^{106}$ an unrelated person with speech and language impairment was found with a chromosomal translocation involving the locus. Characterisation of the chromosomal rearrangement led to the identification of the gene FOXP2, which encodes a putative transcription factor containing a DNA binding domain termed forkhead (abbreviated to FOX). ${ }^{107} \mathrm{~A}$ G to A nucleotide transition was detected in exon 14 of affected persons in the three generation pedigree, and shown to cosegregate perfectly with the speech and language disorder. These findings suggest that FOXP2 is involved at some level in speech and language.

Although it is still too early to be definite about the function of the FOXP2 gene, evidence from other members of the forkhead family suggest that it plays a key part in development. Studies of mutations in human and mouse FOX genes indicate that the resulting disorders are a consequence of haploinsufficiency during embryological development. ${ }^{108-113}$ Duplications involving FOXCl are known to cause defects of the anterior chamber of the eye $\mathrm{e}^{114} 115$ providing further evidence that the phenotype arises through a pertubation of gene dosage. Investigation of the function of FOXP2 is extremely likely to result in new insights into the molecular basis of speech and language development.

\section{CONCLUSIONS}

In general we can conclude that the relation between genetic abnormalities and cognitive processes is still poorly understood, but that there has been considerable recent progress, so that in the next few years we can expect to have a much clearer picture of the biological basis of cognition. To date, the common pathways involved in mental retardation pathogenesis are defects in synapses, axon maintenance, and trafficking. This raises the exciting possibility that work on CNS development will overlap with that on the genetics of mental retardation. ${ }^{116-118}$ It is likely that in the coming years we will see new discoveries in this field.

The success of genetic and molecular dissection of cognition rests on two assumptions. The first of these is that there should be a relatively immediate relation between gene and cognitive phenotype. The data we have reviewed show that 
there is evidence for relatively immediate genetic effects and that, to some extent, the phenotype can be a guide. Investigation of non-syndromic mental retardation has pointed to the importance of Rho- and Rab-GTPase proteins, and mutations in transcriptional regulators are the cause of the complex phenotypes seen in Rett and ARTX syndromes. Regulators of Rho and Rab-GTPase may be what we are looking for, causally much closer to the cognitive impairment than the transacting factors MECP2 and ATRX.

Yet we have also seen that advances in our understanding of two syndromal causes of mental retardation, fragile $\mathrm{X}$ and Prader-Willi syndromes, disclose mechanisms for genetic effects that seem to be relatively immediate causes of cognitive impairment. The striking finding that the fragile X gene product (FMRP) is involved in the synaptic regulation of protein synthesis together with the realisation that protein synthesis in dendrites may be a critical step in learning and memory provides the first glimpse of how mental retardation arises in the fragile $\mathrm{X}$ syndrome. Thus we can give qualified support to the first of the assumptions and expect that further progress in the molecular characterisation of these syndromes will be helpful in explaining the genesis of cognition.

The molecular data also demonstrate that the nosological categories in mental retardation are becoming misleading. The examples we have discussed, of Coffin-Lowry, ATRX, and Rett syndromes show how different mutations in the same genes can result in different phenotypes; some have multiple anomalies, some only mild mental retardation. This finding has important consequences.

Firstly, it suggests that many cases of idiopathic mental retardation, whether mild, moderate, or severe, could be due to mutations in the genes that have already been identified. Therefore mental retardation may not be as aetiologically complex as suspected. Secondly, it means that we may be able to use the analysis of mutations within these genes to see how mental retardation can arise genetically. The discovery of nonsyndromic mental retardation arising from mutations in genes that are implicated in syndromic mental retardation suggests that the cognitive disability is relatively directly caused by the mutation. Thirdly, it is possible that in the neurobiology of cognitive functions we should categorise cases by temporal and spatial expression of functional domains, not by mutated genes or by phenotypes.

The second assumption behind the hope that we will understand the biology of cognition from studying mental retardation syndromes, is that we will find in these patients a cognitive phenotype, in a fractionated pattern, which represents the modularity often assumed to underlie brain function. If this is so, then we can draw conclusions about normal processes from studying the molecular basis of the abnormal.

There is sufficient evidence from neuroimaging and brain lesion studies to support the modular hypothesis in the adult brain, but the extent to which it pertains throughout development is still unknown. One view is that early in life the brain is not specialised and only acquires modularity during development. An investigation of infants with Williams syndrome has been used to address this question. ${ }^{119}$

Williams syndrome is due to a microdeletion on chromosome $7 \mathrm{q}$ and has a characteristic uneven cognitive profile. Overall intelligence quotient scores lie between 50 and 60, with relatively good verbal and relatively deficient visuospatial abilities. ${ }^{120}$ Paterson et al gave tests of vocabulary recognition and number skills to toddlers, age matched controls, and children with Down's syndrome who have a similar IQ. The prediction from the findings in adults is that the Willams syndrome children should perform better on the vocabulary test than on the number skills test. However the researchers found the opposite: toddlers with Williams syndrome did better than children with Down's syndrome on the number task and performed equally well on the vocabulary test.
These results do not argue against modularity, but rather that the relation between modules, genes, and phenotype is likely to be very complex. However, careful investigation of a phenotype may disclose modules that are more tractable to dissection than others. One of the problems in the psychological characterisation of genetic syndromes has been continuing difficulty in finding appropriate measures. For example, Jarrold et al have examined short term memory difficulties in Down's and Williams syndromes. Their evidence for working memory deficits provides an explanation for the cognitive profile that does not involve a defect in a specific language system and support the view that working memory can be dissociated into separate subsystems. ${ }^{121}{ }^{122}$

In summary, there has been remarkable progress in delineating the genetic basis of mental retardation and we now have clues as to which pathways are involved in cognition. But there are still far more conditions the aetiology of which is unknown: perhaps the largest gap in our knowledge is the genetic basis of autosomal mental retardation. Further progress requires continuing collaboration between clinicians and scientists to identify patients from whom we may learn more about the biology of cognition and to provide more detailed information about the nature of the cognitive impairments that arise from genetic mutations.

\section{ACKNOWLEDGEMENTS}

This work has been supported by Academy of Finland, Arvo and Lea Ylppö Foundation, Finnish Medical Foundation, and the Wellcome Trust.

\section{Authors' affiliations}

P Nokelainen, J Flint, Wellcome Trust Centre for Human Genetics, Roosevelt Drive, Oxford OX3 7BN, UK

\section{REFERENCES}

1 Crawley JN, Belknap JK, Collins A, et al. Behavioral phenotypes of inbred mouse strains: implications and recommendations for molecular studies. Psychopharmacology (Berl) 1997;132:107-24.

2 de Belle JS, Heisenberg M. Expression of Drosophila mushroom body mutations in alternative genetic backgrounds: a case study of the mushroom body miniature gene $(\mathrm{mbm})$. Proc Natl Acad Sci U S A 1996;93:9875-80

3 Plomin R. Genetic factors contributing to learning and language delays and disabilities. Child Adolesc Psychiatr Clin N Am 2001:10:259-77.

4 Plomin R, Craig I. Genetics, environment and cognitive abilities: review and work in progress towards a genome scan for quantitative trait locus associations using DNA pooling. Br J Psychiatry Suppl 2001;40:s41-8.

5 Lamb JA, Moore J, Bailey A, et al. Autism: recent molecular genetic advances. Hum Mol Genet 2000;9:861-8.

6 Grigorenko EL. Developmental dyslexia: an update on genes, brains, and environments. J Child Psychol Psychiatry 2001;42:91-125.

7 Maecker HT, Todd SC, Levy S. The tetraspanin superfamily: molecular facilitators. FASEB J 1997; 11:428-42.

8 Grotewiel MS, Beck CD, Wu KH, et al. Integrin-mediated short-term memory in Drosophila. Nature 1998;391:455-60.

9 Connolly JB, Tully T. Integrins: a role for adhesion molecules in olfactory memory. Curr Biol 1998;8:R386-9.

10 Zemni R, Bienvenu T, Vinet MC, et al. A new gene involved in X-linked mental retardation identified by analysis of an $\mathrm{X} ; 2$ balanced translocation. Nat Genet 2000;24:167-70.

11 Tsien JZ, Huerta PT, Tonegawa S. The essential role of hippocampal CA 1 NMDA receptor-dependent synaptic plasticity in spatial memory. Cell 1996:87: 1327-38.

12 Carrie A, Jun L, Bienvenu T, et al. A new member of the IL-1 receptor family highly expressed in hippocampus and involved in X-linked mental retardation. Nat Genet 1999;23:25-31

13 lacovelli L, Sallese M, Mariggio S, et al. Regulation of G-protein-coupled receptor kinase subtypes by calcium sensor proteins. FASEB J 1999;13:1-8.

14 Martone ME, Edelmann VM, Ellisman MH, et al. Cellular and subcellular distribution of the calcium-binding protein NCS-1 in the central nervous system of the rat. Cell Tissue Res 1999;295:395-407.

15 Van Aelst L, D'Souza-Schorey C. Rho GTPases and signalling networks. Genes Dev 1997;11:2295-322.

16 Mackay DJ, Hall A. Rho GTPases. J Biol Chem 1998;273:20685-8.

17 Hall A. Rho GTPases and the actin cytoskeleton. Science 1998;279:509-14

18 Luo L, Hensch TK, Ackerman L, et al. Differential effects of the Rac GTPase on Purkinje cell axons and dendritic trunks and spines. Nature 1996;379:837-40 
19 Billuart P, Bienvenu T, Ronce N, et al. Oligophrenin-1 encodes a rhoGAP protein involved in X-linked mental retardation. Nature 1998;392:923-6.

20 Kutsche K, Yntema H, Brandt A, et al. Mutations in ARHGEF6, encoding a guanine nucleotide exchange factor for Rho GTPases, in patients with X-linked mental retardation. Nat Genet 2000:26:247-50.

21 Allen KM, Gleeson JG, Bagrodia S, et al. PAK3 mutation in nonsyndromic X-linked mental retardation. Nat Genet 1998;20:25-30.

22 Sells MA, Knaus UG, Bagrodia S, et al. Human p21-activated kinase (Pak1) regulates actin organization in mammalian cells. Curr Biol 1997; 7:202-10

23 D'Adamo P, Menegon A, Lo Nigro C, et al. Mutations in GDI1 are responsible for X-linked non-specific mental retardation. Nat Genet 1998; 19:134-9.

24 Nobles C, Hall A. Rho, Rac, and Cdc42 GTPases regulate the assembly of multimolecular focal complexes associated with actin stress fibres, lamellipoia and filopodia. Cell 1995;81:53-62.

25 Threadgill R, Bobb K, Ghosh A. Regulation of dendriic growth and remodelling by Rho, Rac and Cdc42. Neuron 1997;19:625-34.

26 Sudhof TC. The synaptic vesicle cycle: a cascade of protein-protein interactions. Nature 1995;375:645-53.

27 Geppert M, Bolshakov VY, Siegelbaum SA, et al. The role of Rab3A in neurotransmitter release. Nature 1994;369:493-7.

28 North K. Neurofibromatosis type 1. Am J Med Genet 2000;97: 1 19-27.

29 Ozonoff S. Cognitive impairment in neurofibromatosis type 1. Am J Med Genet 1999:89:45-52.

30 Scheffzek K, Ahmadian MR, Wiesmuller L, et al. Structural analysis of the GAP-related domain from neurofibromin and its implications. EMBO J 1998;17:4313-27

31 Klose A, Ahmadian MR, Schuelke M, et al. Selective disactivation of neurofibromin GAP activity in neurofibromatosis type 1. Hum Mol Genet 1998;7:1261-8.

32 Biancalana V, Trivier E, Weber C, et al. Construction of a high-resolution linkage map for Xp22.1-p22.2 and refinement of the genetic localization of the Coffin-Lowry syndrome gene. Genomics 1994:22:617-25.

33 Bird H, Collins AL, Oley C, et al. Crossover analysis in a British family suggests that Coffin-Lowry syndrome maps to a 3.4-cM interval in Xp22. Am J Med Genet 1995;59:512-6.

34 Hanaver A, Alembik Y, Gilgenkrantz S, et al. Probable localisation of the Coffin-Lowry locus in Xp22.2-p22.1 by multipoint linkage analysis. Am J Med Genet 1988;30:523-30.

35 Trivier E, De Cesare D, Jacquot S, et al. Mutations in the kinase Rsk-2 associated with Coffin-Lowry syndrome. Nature 1996;384:567-70

36 Jacquot S, Merienne K, Trivier E, et al. Coffin-Lowry syndrome: current status. Am J Med Genet 1999:85:214-5.

37 Manouvrier-Hanu S, Amiel J, Jacquot S, et al. Unreported RSK2 missense mutation in two male sibs with an unusually mild form of Coffin-Lowry syndrome. J Med Genet 1999;36:775-8

38 Merienne $\mathrm{K}$, Jacquot S, Pannetier S, et al. A missense mutation in RPS6KA3 (RSK2) responsible for non-specific mental retardation. Nat Genet 1999;22:13-4.

39 Xing J, Ginty DD, Greenberg ME. Coupling of the RAS-MAPK pathway to gene activation by RSK2, a growth factor-regulated CREB kinase. Science 1996:273:959-63.

40 Bardoni B, Mandel JL, Fisch GS. FMR 1 gene and fragile $X$ syndrome. Am J Med Genet 2000;97:153-63.

41 Tassone F, Hagerman RJ, Ikle DN, et al. FMRP expression as a potential prognostic indicator in fragile X syndrome. Am J Med Genet 1999;84:250-61.

42 de Vries BB, Jansen CC, Duits AA, et al. Variable FMR 1 gene methylation of large expansions leads to variable phenotype in three males from one fragile X family. J Med Genet 1996;33:1007-10

43 Taylor AK, Tassone F, Dyer PN, et al. Tissue heterogeneity of the FMR 1 mutation in a high-functioning male with fragile $X$ syndrome. Am J Med Genet 1999:84:233-9.

44 de Vries BB, Wiegers AM, Smits AP, et al. Mental status of females with an FMR 1 gene full mutation. Am J Hum Genet 1996;58:1025-32.

45 Yu S, Pritchard M, Kremer E, et al. Fragile X genotype characterized by an unstable region of DNA. Science 1991;252:1179-81.

46 Pieretti $M$, Zhang F, Fu Y.H, et al. Absence of expression of the FMR-1 gene in fragile $X$ syndrome. Cell 1991;66:817-22.

47 Verkerk AJMH, Pieretti M, Sutcliffe JS, et al. Identification of a gene (FMR-1) containing a CGG repeat coincident with a breakpoint cluster region exhibiting length variation in fragile $X$ syndrome. Cell 1991;65:905-14.

48 Oberle I, Rousseau F, Heitz D, et al. Instability Of a 550 base pair DNA segment and abnormal methylation in fragile X-syndrome. Science 1991;252:1097-102.

49 Eberhart DE, Malter HE, Feng $Y$, et al. The fragile $X$ mental retardation protein is a ribonucleoprotein containing both nuclear localization and nuclear export signals. Hum Mol Genet 1996;5:1083-91.

50 Tamanini F, Meijer N, Verheij C, et al. FMRP is associated to the ribosomes via RNA. Hum Mol Genet 1996:5:809-13.

51 Consortium TD-BFX. Fmr 1 knockout mice: a model to study fragile $X$ mental retardation. Cell 1994;78:23-33.

52 Feng $Y$, Absher D, Eberhart DE, et al. FMRP associates with polyribosomes as an mRNP, and the $1304 \mathrm{~N}$ mutation of severe fragile $X$ syndrome abolishes this association. Mol Cell 1997;1:109-18.

53 Feng $Y$, Gutekunst $C A$, Eberhart $D E$, et al. Fragile $X$ mental retardation protein: nucleocytoplasmic shuttling and association with somatodendritic ribosomes. J Neurosci 1997; 17:1539-47.
54 Khandiian EW, Corbin F, Woerly S, et al. The Fragile X mental retardation protein is associated with ribosomes. Nat Genet 1996; 12:91-3.

55 Single S, Borst A. Dendritic integration and its role in computing image velocity. Science 1998;281:1848-50.

56 Kang $\mathbf{H}$, Schuman EM. A requirement for local protein synthesis in neurotrophin-induced hippocampal synaptic plasticity. Science 1996;273: 1402-6

57 Schuman EM. mRNA trafficking and local protein synthesis at the synapse. Neuron 1999;23:645-8.

58 Ouyang $Y$, Rosenstein A, Kreiman $G$, et al. Tetanic stimulation leads to increased accumulation of $\mathrm{Ca}(2+)$ /calmodulin-dependent protein kinase II via dendritic protein synthesis in hippocampal neurons. J Neurosci 1999; 19:7823-33

59 Aakalu G, Smith WB, Nguyen N, et al. Dynamic visualization of local protein synthesis in hippocampal neurons. Neuron 2001;30:489-502.

60 Steward O, Worley PF. A cellular mechanism for targeting newly synthesized mRNAs to synaptic sites on dendrites. Proc Natl Acad Sci U $S$ A 2001;98:7062-8

61 Steward O, Worley PF. Selective targeting of newly synthesized Arc mRNA to active synapses requires NMDA receptor activation. Neuron 2001;30:227-40.

62 Greenough WT, Klintsova AY, Irwin SA, et al. Synaptic regulation of protein synthesis and the fragile $X$ protein. Proc Natl Acad Sci U S A 2001;98:7101-6.

63 Weiler IJ, Irwin SA, Klintsova AY, et al. Fragile $X$ mental retardation protein is translated near synapses in response to neurotransmitter activation. Proc Natl Acad Sci U S A 1997;94:5395-400.

64 Irwin SA, Swain RA, Christmon CA, et al. Evidence for altered fragile-X mental retardation protein expression in response to behavioral stimulation. Neurobiol Learn Mem 2000;74:87-93.

65 Irwin SA, Galvez R, Greenough WT. Dendritic spine structural anomalies in fragile-X mental retardation syndrome. Cereb Cortex 2000; 10:1038-44.

66 Hinton VJ, Brown WT, Wisniewski K, et al. Analysis of neocortex in three males with the fragile X syndrome. Am J Med Genet 1991:41:289-94.

67 Nicholls RD, Saitoh S, Horsthemke B. Imprinting in Prader-Willi and Angelman syndromes. Trends Genet 1998;14:194-200.

68 Budarf ML, Emanuel BS. Progress in the autosomal segmental aneusomy syndromes (SASs): single or multi-locus disorders. Hum Mol Genet 1997:6:1657-65.

69 Cavaille J, Buiting K, Kiefmann M, et al. Identification of brain-specific and imprinted small nucleolar RNA genes exhibiting an unusual genomic organization. Proc Natl Acad Sci U S A 2000;97:14311-6.

70 Buhot MC. Serotonin receptors in cognitive behaviors. Curr Opin Neurobiol 1997;7:243-54.

71 Wolffe AP, Guschin D. Review: chromatin structural features and targets that regulate transcription. J Struct Biol 2000;129:102-22.

72 Hagberg B, Goutieres F, Hanefeld F, et al. Rett syndrome: criteria for inclusion and exclusion. Brain Dev 1985;3:372-3.

73 Schanen NC, Kurczynski TW, Brunelle D, et al. Neonatal encephalopathy in two boys in families with recurrent Rett syndrome. $J$ Child Neurol 1998;13:229-31.

74 Bienvenu T, Carrie A, de Roux N, et al. MECP2 mutations account for most cases of typical forms of Rett syndrome. Hum Mol Genet 2000;9:1377-84.

75 Hoffbuhr K, Devaney JM, LaFleur B, et al. MeCP2 mutations in children with and without the phenotype of Rett syndrome. Neurology 2001;56:1486-95.

76 Couvert P, Bienvenu T, Aquaviva C, et al. MECP2 is highly mutated in $X$-linked mental retardation. Hum Mol Genet 2001;10:941-6.

77 Amir RE, Van den Veyver IB, Wan M, et al. Rett syndrome is caused by mutations in X-linked MECP2, encoding methyl-CpG-binding protein 2. Nat Genet 1999:23:185-8.

78 Lewis JD, Meehan RR, Henzel WJ, et al. Purification, sequence, and cellular localization of a novel chromosomal protein that binds to methylated DNA. Cell 1992;69:905-14.

79 Bird AP, Wolffe AP. Methylation-induced repression: belts, braces, and chromatin. Cell 1999:99:451-4.

80 Nan X, $\mathrm{Ng} \mathrm{HH}$, Johnson CA, et al. Transcriptional repression by the methyl-CpG-binding protein MeCP2 involves a histone deacetylase complex. Nature 1998;393:386-9.

81 Jones PL, Veenstra GJ, Wade PA, et al. Methylated DNA and MeCP2 recruit histone deacetylase to repress transcription. Nat Genet 1998;19:187-91.

82 Wade PA, Jones PL, Vermaak D, et al. Histone deacetylase directs the dominant silencing of transcription in chromatin: association with MeCP2 and the Mi-2 chromodomain SWI/SNF ATPase. Cold Spring Harb Symp Quant Biol 1998;63:435-45.

83 Wan M, Lee SS, Zhang X, et al. Rett syndrome and beyond: recurrent spontaneous and familial MECP2 mutations at CpG hotspots. Am J Hum Genet 1999;65:1520-9.

84 Gibbons RJ, Higgs DR. Molecular-clinical spectrum of the ATR-X syndrome. Am J Med Genet 2000;97:204-12.

85 Gibbons RJ, Picketts DJ, Villard L, et al. Mutations in a putative global transcriptional regulator cause $X$-linked mental retardation with $\alpha$-thalassemia (ATR-X Syndrome). Cell 1995;80:837-45

86 Gibbons RJ, McDowell TL, Raman S, et al. Mutations in ATRX, encoding a SWI/SNF-like protein, cause diverse changes in the pattern of DNA methylation. Nat Genet 2000;24:368-71.

87 Guerrini R, Shanahan JL, Carrozzo R, et al. A nonsense mutation of the ATRX gene causing mild mental retardation and epilepsy. Ann Neurol 2000;47:117-21. 
88 Martinez F, Tomas M Millan JM et al. Genetic localisation of mental retardation with spastic diplegia to the pericentromeric region of the $X$ chromosome: $X$ inactivation in female carriers. J Med Genet 1998;35:284-7

89 Picketts DJ, Higgs DR, Bachoo S, et al. ATRX encodes a novel member of the SNF2 family of proteins: mutations point to a common mechanism underlying the ATR-X syndrome. Hum Mol Genet 1996;5: 1899-907.

90 Youings SA, Murray A, Dennis N, et al. FRAXA and FRAXE: the results of a five year survey. J Med Genet 2000;37:415-21.

91 Hamel BC, Smits AP, de Graaff E, et al. Segregation of FRAXE in a large family: clinical, psychometric, cytogenetic and molecular data. Am J Hum Genet 1994;55:923-31.

92 Knight SJL, Ritchie RJ, Chakrabarti L, et al. A study of FRAXE in mentally-retarded individuals referred for fragile-X syndrome (FRAXA) testing in the United Kingdom. Am J Hum Genet 1996:58:906-13.

93 Abrams MT, Doheny KF, Mazzocco MM, et al. Cognitive, behavioral, and neuroanatomical assessment of two unrelated male children expressing FRAXE. Am J Med Genet 1997;74:73-81.

94 Gecz J, Bielby S, Sutherland GR, et al. Gene structure and subcellular localization of FMR2, a member of a new family of putative transcription activators. Genomics 1997:44:201-13.

95 Miller WJ, Skinner JA, Foss GS, et al. Localization of the fragile X mental retardation 2 (FMR2) protein in mammalian brain. Eur J Neurosci 2000; 12:381-4.

96 Gedeon AK, Meinanen M, Ades LC, et al. Overlapping submicroscopic deletions in Xq28 in two unrelated boys with developmental disorders: identification of a gene near FRAXE. Am J Hum Genet 1995;56:907-14.

97 Gu Y, Shen Y, Gibbs RA, et al. Identification of FMR2, a novel gene associated with the FRAXE CCG repeat and CpG island. Nat Genet 1996;13:109-13.

$98 \mathrm{Gecz} \mathrm{J}$, Gedeon AK, Sutherland GR, et al. Identification of the gene FMR2, associated with FRAXE mental retardation. Nat Genet 1996;13:105-8.

99 Gecz J, Oostra BA, Hockey A, et al. FMR2 expression in families with FRAXE mental retardation. Hum Mol Genet 1997:6:435-41.

$100 \mathrm{Gecz}$ J. FMR3 is a novel gene associated with FRAXE CPG island and transcriptionally silent in FRAXE full mutations. J Med Gene 2000;37:782-4

101 Hurst JA, Baraitser M, Auger E, et al. An extended family with a dominantly inherited speech disorder. Dev Med Child Neurol 1990;32:347-55.

102 Gopnik M. Feature-blind grammar and dysphagia. Nature 1990;344:715.

103 Gopnik M. Genetic basis of grammar defect. Nature 1990;347:26.

104 Gopnik M. Crago MB. Familial aggregation of a developmental language disorder. Cognition 1991;39:1-50.

105 Vargha-Khadem F, Watkins K, Alcock K, et al. Praxic and nonverbal cognitve deficits in a large family with a genetically transmitted speed and language disorder. Proc Natl Acad Sci USA 1995;92:930-3.
106 Fisher SE, VarghaKhadem F, Watkins KE, et al. Localisation of a gene implicated in a severe speech and language disorder. Nat Genet. 1998; 18:168-70

107 Lai CS, Fisher SE, Hurst JA, et al. A forkhead-domain gene is mutated in a severe speech and language disorder. Nature 2001;413:519-23.

108 Biggs WH 3rd, Cavenee WK. Identification and characterization of members of the FKHR (FOX O) subclass of winged-helix transcription factors in the mouse. Mamm Genome 2001;12:416-25.

109 Osborne LR. "Forkhead" gene expression balanced on a knife-edge. Trends Mol Med 2001;7:51

110 Crisponi L, Deiana $M$, Loi $A$, et al. The putative forkhead transcription factor FOXL2 is mutated in blepharophimosis/ptosis/epicanthus inversus syndrome. Nat Genet 2001;27:159-66.

111 Semina EV, Brownell I, Mintz-Hittner HA, et al. Mutations in the human forkhead transcription factor FOXE3 associated with anterior segment ocular dysgenesis and cataracts. Hum Mol Genet 2001;10:231-6.

112 Brunkow ME, Jeffery EW, Hjerrild KA, et al. Disruption of a new forkhead/winged-helix protein, scurfin, results in the fatal ymphoproliferative disorder of the scurfy mouse. Nat Genet 2001;27:68-73.

113 Fang J, Dagenais SL, Erickson RP, et al. Mutations in FOXC2 (MFH-1), a forkhead family transcription factor, are responsible for the hereditary lymphedema-distichiasis syndrome. Am J Hum Genet 2000;67:1382-8.

114 Lehmann OJ, Ebenezer ND, Jordan T, et al. Chromosomal duplication involving the forkhead transcription factor gene $\mathrm{FOXCl}$ causes iris hypoplasia and glaucoma. Am J Hum Genet 2000;67:1129-35.

115 Nishimura DY, Searby CC, Alward WL, et al. A spectrum of FOXC 1 mutations suggests gene dosage as a mechanism for developmental defects of the anterior chamber of the eye. Am J Hum Genet $2001 ; 68: 364-72$

116 Edlund T, Jessell TM. Progression from extrinsic to intrinsic signaling in cell fate specification: a view from the nervous system. Cell 1999;96:211-24.

117 Stein E, Tessier-Lavigne M. Hierarchical organization of guidance receptors: silencing of netrin attraction by slit through a Robo/DCC receptor complex. Science 2001;291:1928-38.

118 Zou Y, Stoeckli E, Chen H, et al. Squeezing axons out of the gray matter: a role for slit and semaphorin proteins from midline and ventra spinal cord. Cell 2000;102:363-75.

119 Paterson SJ, Brown JH, Gsodl MK, et al. Cognitive modularity and genetic disorders. Science 1999;286:2355-8.

120 Francke U. Williams-Beuren syndrome: genes and mechanisms. Hum Mol Genet 1999;8:1947-54.

121 Jarrold C, Baddeley AD, Hewes AK. Genetically dissociated components of working memory: evidence from Down's and Williams syndrome. Neuropsychologia 1999;37:637-51.

122 Jarrold C, Baddeley AD, Phillips C. Down syndrome and the phonological loop: the evidence for, and importance of, a specific verbal short-term memory deficit. Downs Syndr Res Pract 1999;6:61-75. 